\title{
Beyond the OSA optics discovery kit
}

\section{Donald O'Shea}

Donald C. O'Shea, "Beyond the OSA optics discovery kit," Proc. SPIE 3190, Fifth International Topical Meeting on Education and Training in Optics, (8 December 1997); doi: 10.1117/12.294386

SPIE Event: Fifth International Topical Meeting on Education and Training in Optics, 1997, Delft, Netherlands 
Invited Paper

\title{
Beyond the OSA Optics Discovery Kit
}

\author{
Donald C. O'Shea \\ Georgia Institute of Technology, School of Physics \\ Atlanta, Georgia 30332-0430
}

\begin{abstract}
Having designed a kit of optics components with simple experiments for the Optical Society of America, there was a question: "What, if anything, do you do for an encore?" This talk will look at several possibilities for introducing the public to science, in general, and optics, in particular.
\end{abstract}

KEYWORDS: optics education, science education, pedagogy, popular culture.

\section{INTRODUCTION}

As a youngster I used to collect lenses and mirrors in a cigar box to be used for my experiments in optics. Later I found that I could buy lenses from Edmund Salvage Company, a company that sold salvaged war parts, many of them optical components. But Edmund went beyond simply salvaging optics, because they also included simple plans for making optical instruments such as opaque projectors and telescopes with their components. Later, this interest was converted to a professional activity as a teacher of optics at Georgia Tech. At that time there was a packet of components that could be purchased as part of the Berkeley physics series, a sequence of undergraduate texts that included the direct experience of the student as a necessary part of the curriculum. The packet contained a series of polarizers and wave plates, a diffraction grating and color filters. The entire package, which is not longer available, was only a little bigger and bulkier than a large tea bag. All the above instances contributed to the generation of the OSA Optics Discovery Kit. ${ }^{1}$

With the publication of several studies that indicated that American students were neither interested in nor equipped to study science and mathematics, the Optical Society of America, a non-profit professional organization, established an education committee and charged them with developing projects that would assist both the members and the general public in the teaching and the promotion of optics as a profession. The committee established a number of education projects that led professional societies in the field including an OSA Summer Fellow, education grants for elementary and high school teachers, an education column in the OSA magazine, Optics and Photonics News, a graduate student seminar at the Annual Meeting, a database of optics education in the United States and Canada, and resources for education in optics. The resource subcommittee of the Education Council was organized to look into methods of providing students and teachers with the tools needed to promote interest in science in general and optics in particular. As chair of the subcommittee I decided to investigate the possibility of providing optical components for students and teachers. My ideas grew out of my earlier experiences with cheap lenses, optics with instructions to build instruments, and the compact little packs of the Berkeley Physics Series.

Besides the perceived the decline of interest in science by students, there was another problem that I was trying to address-the loss of fascination in technology. Children are not removed from technology. Far from it! They are immersed in it. But they do not understand it and cannot be fascinated by it as its bases are hidden. Technology appears almost as magic. Consider the alarm clock that may have waked you up this morning. Do you know how it works? Could you, clever reader that you are, open it up, and disassemble it so that you could determine how it works? Probably not. You would be confronted by a printed circuit board, or more likely a single chip, and a battery attached to an LED display and a couple of switches. But if we were to go back to the time when I kept my lenses in a cigar box, a child could open up an alarm clock, study it, watch the wheels advance from the spring-driven mechanism, and begin to understand how the clock and its alarm worked. You could even set the alarm off again and again, much to the distraction of your mother. Today, what is true of mechanical mechanisms is true also of optics. With the possible exception of throwaway cameras, it is difficult to find a lens in everyday life that child can examine and play with. Even in the case of the camera lenses, they tend to be small and hard to handle. So, another strong motivation for the optics kit was to put simple, easy to handle optical components into a child's hands. 


\section{THE OSA OPTICS DISCOVERY KIT}

Although a complete description of the OSA Optics Discovery Kit was given in the Proceedings of an earlier conference, I would like to briefly describe the kit, so that it is clear what is it I am trying to go "beyond." At the outset, my concept was an optics junkshop: a collection of a number of optical components that a child could play with. The emphasis was and has remained on discovery rather than formal teaching. That doesn't mean, however, that the kit cannot and has not been used as part of established teaching programs.

The first consideration was the contents of the kit. The heart of the kit is a set of three lenses, two positive lenses, one short focal length lens and one long one, and a negative lens. The lenses are centered in a tablet shaped like a tombstone. The tablet has a ridge around the edge that protects the lens when it is laid on a flat surface. The tablet design is particularly useful for children since anyone not familiar to optics tends to pick up a lens in the middle rather than holding it by its edges. Some of the other components for the kit are obvious choices: a diffraction grating, two polarizers, four color filters. Other choices were a matter of opportunity or luck. I wanted a Fresnel lens for the kit, but the ones I could find were too expensive for the kit. We were able to find one that was used with boxes for collecting bugs at a price comparable to the other components in the kit. To emphasize the more modern aspects of optics we included a meter of optical fiber and a hologram. I wanted a mirror in the kit, but a shiny flat mirror might be either too fragile if made of glass or easily destroyed if made of a metal. I chose a flexible plastic mirror because it would be fun to play with and it was cheap. It could be used as a portable fun-house mirror. The color filters are standard gel filters from a theatrical supply house and the diffraction grating was purchased from my old optics source, Edmund Scientific.

While it would be nice to think that putting these components in the hands of a kid would result in an immediate appreciation of optics, it is more likely that most children would find the items mildly interesting, but would not know what to do with them. To this end a set of short experiments was devised to illustrate the use of the items in the kit. None of the experiments is very difficult or elaborate. This is, after all, intended as a discovery kit. The description of the experiments was modeled after the simple displays used in conjunction with the exhibits at the Exploratorium science museum in San Francisco. The items needed are listed above a diagram of the experiment. Below is a simple description of the actions to be carried out and a short list of questions to guide the user in the discovery. This is followed by an explanation of the experiment without using equations and a short note on how the components are useful in daily life or important for new technology. The format is shown in Fig. 1 and a list of the experiments is given in Table 1.

Table 1. List of experiments in the OSA Optics Discovery Kit.

1. Lenses. Concept of images and focal length of lenses.

2. Magnifiers. Magnified images and estimation of magnification.

3. Galilean Telescope. Magnification and orientation of images.

4. Keplarian Telescope. Magnification and orientation of images.

5. Fresnel Lens. Comparison with other lenses, focal length.

6. Projector. Real images, magnification, optical illusions.

7. Diffraction Grating. Optical spectrum, filtering of light.

8. Polarizers. Polarization, stress birefringence.

9. Mirrors. Real and virtual images in a spoon, bendable mirrors.

10. Holograms. Observation of a hologram.

11. Optical Fiber. Transmission of light by a fiber.

To assist teachers, a manual was written by an OSA Summer Fellow, George Smeller, a high school teacher. Each student experiment page was followed by a teacher's section divided into four short parts. The first, Notes on Set-up, was intended to give basic information on the optimal classroom conditions for the experiment. The second, Expected Results, answers the questions raised in the activities section of the experiment sheet. The third section, Discussion Questions, is intended to take the experiment beyond the experiment sheet. Finally, there is a list of Additional Activities for More Advanced Students. Recently, plans have been instituted to make an instructional video for teachers using the kit. This will be a joint project between OSA and SPIE under the leadership of Dr. James Bilbro of NASA Marshall Spaceflight Center.

The first kits were assembled in plastic Baggies in my laboratory with the help of some of my graduate students. They were given out at OSA-sponsored Educators' days. Each teacher was given a kit, a set of the experiments and a teacher's 
manual. In the afternoon we presented a workshop that described the components and went over each of the experiments. But the distribution was modest and it would never fulfill my secretly-held goal that the lenses in the kit would be found in between the cushions of every couch in America. I continually asked by the teachers when and where they could buy the kits, but I had no idea when OSA would be able to sell them. The production of the kits eluded me. I am college professor, not marketing person. The savior of the Optics kit was Paul Forman, who was asked by OSA to be the liaison between the Education and Engineering Councils. Paul, who was president of Zygo Corporation, took it upon himself to investigate their use and distribution. He generated a marketing plan to move cautiously toward the manufacture and distribution of the kits. He determined the costs and set up the procedure for beginning assembly of the kits. Until recently, OSA has been responsible for the kit assembly. This is not the kind of work a professional society is particularly good at doing. A new strategy, involving our friends at Edmund Scientific, is being put into place along with eye-catching new packaging using videotape cases.

There are actually two kits: a kit consisting of one of each of the items described above, called a Single Kit, and a Classroom Kit, that has 16 of each item, a page on each experiment that can be copied, and the Teacher's Manual. In the first 6 years of the kit, there were about 10,000 kits sold. From a sampling of the orders placed in that period, it was found that the majority of kits $(40 \%)$ were sold to corporations. It is thought that these kits were not used by the businesses in their own training, but by the employees to support science teaching in their local schools. The second largest source of buyers was from colleges and universities. Again, the motivation was probably for support of local education, although there is an example, as we will see later, that does use the kit for science teaching at the university level. Distribution and sales of the kits to science museums and educational supply companies have not been possible, because of the mark up in prices required by these institutions to produce a profit would make the kits too expensive.

\section{WHAT DO YOU DO FOR AN ENCORE?}

Having launched what some feel is a very successful venture, shouldn't one, just like in the movies, try to come up with a sequel? If the movies are any guide, the answer in most cases should be "No." Still, are there areas of optics or a different level of student that could be helped by some other type kit?

After the kit was finally launched, those of us working on it were told that there was a ready supply of light emitting diodes and detectors available for use in the kits. Some of these would be given to us. After playing around with the possibilities for some time I designed a kit that illustrated some of the principles of radiometry. Using the Fresnel lens and color filters of the Discovery kit in conjunction with the LEDs and a detector, I set up a compact optics bench that could demonstrate a number of radiometric principles. I simplified the bench with its component carriers to some simple cardboard and rubber band holders on a cardboard lens bench (Fig. 2). The entire set of components could be nested in the hollow of the cardboard sheets, so that the entire kit could fit in a standard-size office envelope. The only sticking point in the design was the need for a detector readout. Since I didn't feel we could ship a voltmeter or oscilloscope with each kit, I devised a small minicalculator-size readout to which two detectors would be attached. One detector would be a $1 \mathrm{~cm}^{2}$ photodiode, the other a small area PIN photodiode. It really looked promising.

But two things happened. First, I couldn't find anyone who could tell me how to get my miniature photodetection package fabricated. And second, I started thinking. Who would use the kit? How many would be needed? What level would the kit be directed toward? I decided only a few hundred per year would be built and the level would be so high that I would not be fulfilling one of my goals, to encourage early interest in optics in particular and science in general. So I abandoned he project, but not the goal.

At this time I had begun to work in the field of diffractive optics and learned a good deal about generating and replicating diffractive optical elements. A variety of lenses and gratings could be embossed on a plastic sheet and an amazing number of components could be packed on it. At the same time laser pointers were becoming less expensive. What if a number of optical surfaces could be embossed on a large sheet of plastic and the sheet could be cut up into pieces that are 2.5" $(62 \mathrm{~cm})$ by $3.5^{\prime \prime}(87 \mathrm{~cm})$ and combined with printed cards of the same size. On the printed cards would be descriptions of the experiment or experiments that could be done with the surface embossed on the plastic plus information on other areas of optics, short biographies of noted scientists and engineers, and natural optical phenomena. If packaged in bundles of 6 to 10 cards each, you would have a set of Optics Trading Cards (Fig. 3)! This popular publishing format for children could be used to provide another method of introducing science to kids. Also, the format is such that the price for a set would be much less 
that the Optics Discovery Kit. Nothing has happened to this idea, yet. But I am still hopeful that I can generate some interest in the project. This paper is yet another advertisement for the Cards.

\section{SUPPOSE THERE IS NO ENCORE?}

Perhaps we don't need anymore "things." Maybe there are other ways to provide curiosity generators. Because the purpose of all these efforts is to generate student interest, any technique or method that can assist in this objective should be considered. "Things" cost money and they have to be made, stored, packaged, and sold. The Kit and the Cards are examples of this problem. Are there other ways to get/permit children to play with optics?

Another possibility is to use the Internet to provide experiences. Although there is a good deal of educational material already on the Net, much of it is intended as resource material rather than as motivational material. That is not to say there are not some sites that provide excitement and information on some aspect of a scientific endeavor. But what is available in optics education? The following is a brief survey of what I have been able to find.

There is material on the OSA Optics Discovery Kit. This appears on the OSA web pages ${ }^{2}$ as information on the content and purchase of the kits from OSA. A better description of the kit is given by Steve Beeson of Arizona State University ${ }^{3}$ as part of their ACEPT program. This kit is used in conjunction with a course on Light and Color ${ }^{4}$ that includes modules on Light, Reflection, and Refraction; Lenses, Mirrors, and Prisms; Color and the Spectrum; and Optics in Nature plus supplementary modules

Also available on the web are number of sites that provide descriptions of optics experiments. The student chapter of OSA at the University of Rochester has an Optics Roadshow that is described on one of their pages. ${ }^{5}$ Although the descriptions are terse, most optics people can determine the content of the demonstrations. In conjunction with the 1996 annual meeting, Wayne Knox of Bell Labs assembled a number of simple experiments on optics. ${ }^{6}$ Bruce Irving of Optical Research Associates, the company responsible for Code V lens design software, has established a page called "Optics for Kids," a brief description of basic optics and lenses presented in a non-condescending manner." It is a good place to send a child who wants to know more about optics. Finally, there is the Exploratorium page ${ }^{8}$. It has a number of interactive sections. One, a discovery sequence on light and shadows, is completely discovery-based with no analysis of the phenomena. Some scientists may find the site a bit off-putting since there is no analysis and conclusion. But it does illustrate the delight of discovery and paths that it can take. There is also an illustrated description of the dissection of a cow's eye. While fairly graphic, it is obvious that an actual dissection is the only way to really see what a cow's eye is like.

I think that we in the optics education community have some work to do along these lines. Consider the possibilities of using Java in various simulations. Although it will not put working lenses into a student's hands, simulations with photos of real experiments might bridge the gap. The limitation in this method certainly shows in the presentation of holograms on the web ${ }^{9}$. Still, there are ideas and experiments that can be presented on the web. One example taken from the publishing community is a simple discussion of color presentation on the web ${ }^{10}$ by John McWade, a graphic designer and publisher of a how-to magazine on design. If you examine this example, you will find that the presentation of material on the web takes much thought and design.

So perhaps the next effort by the optics education community should be to generate a series of "Optics Experiments for the Web." These should include not only simulations, but information, perhaps in a format very similar to the Optics Trading Cards since the concept has much appeal both from a design standpoint and from brevity of effective presentations on the Internet. It could be a site sponsored by one of the professional societies with an editor that would accept, evaluate, and publish contributions from teachers and researchers. It might provide excellent projects for one or more student optics clubs. If this has some success, maybe I can stop thinking about what is beyond the OSA Optics Discovery Kit. 


\section{REFERENCES}

${ }^{1}$ D. C. O’Shea, “The Optics Discovery Kit,” SPIE Ed. Conf., St. Petersburgh, Russia, 1990.

${ }^{2}$ http://w3.osa.org/Ctalog/lms-odk.htm. Note: this and all other HTMLs were current at the time of the presentation of the paper, but web pages do not remain at the same point forever. Therefore, there may be some changes after this is published. In many cases, a detailed search will turn up the new site for the page.

${ }^{3} \mathrm{http} / / /$ acept.la.asu.edu/PiN/mod/light/patt_odk.html

${ }^{4}$ http://acept.la.asu.edu/PiN/mod/light/pattLightOptics.html

${ }^{5} \mathrm{http}: / /$ www.optics.rochester.edu:8080/OSA/roadshow/rdshw.htm

${ }^{6} \mathrm{http} / / /$ w3.osa.org/MTG_CONF/ANNUAL/1996/POSTMEET/EDUFORUM/DEFAULT.HTM

${ }^{7} \mathrm{http}: / /$ www.opticalres.com/kidoptx.html

${ }^{8} \mathrm{http} / / / \mathrm{www}$. exploratorium.edu/

${ }^{9} \mathrm{http} / / /$ web.mit.edu/museum/collections/holography.html

${ }^{10} \mathrm{http}: / / \mathrm{www}$.pagelab.com/ 


\section{EXPERIMENT \#5 \\ FRESNEL (Freh'-Nell) LENS}

EQUIPMENT: Fresnel Lens, Lenses A,B and C, Ruler and Screen

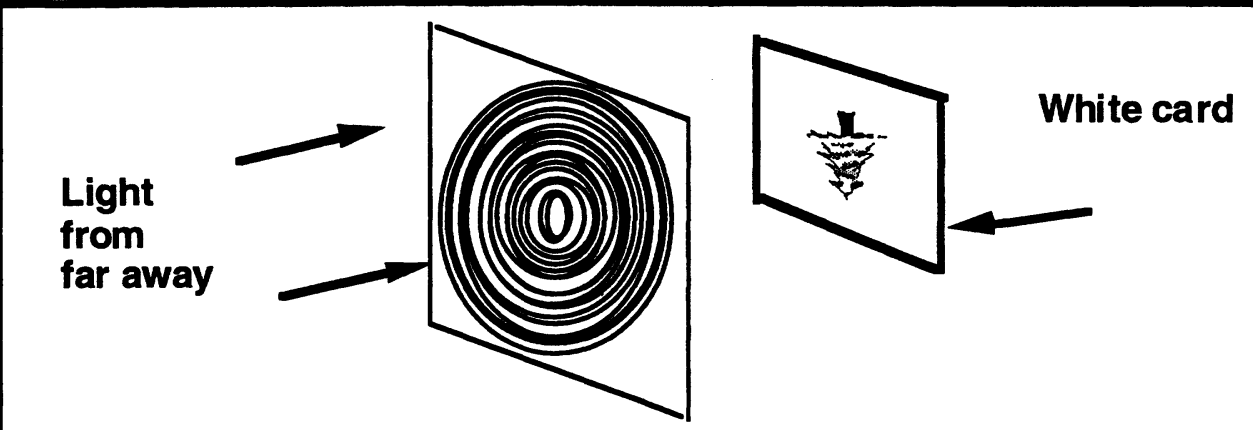

\section{CAUTION! DO NOT LOOKAT THE SUN!}

COMPARE Look closely and carefully at the Fresnel lens. 1) Tell how the

LENSES Fresnel lens appears different from the other lenses. 2) Is the Fresnel lens a magnifier? (Look back to Experiment \#2 if you have forgotten how to tell.)

FIND THE In Experiment \#1 you found the focal lengths of some of the lenses.

FOCAL Using a small, bright object (such as a light bulb) which is very far

LENGTH from the Fresnel lens, and the white card, find the focal length of the lens. 3) What is the focal length of the Fresnel lens?

MAKE A The Fresnel lens can be used along with one of the other lenses to make

TELESCOPE a telescope. Choose one of the other lenses and make a telescope. 4) Figure out which type of telescope (Galilean or Keplerian) you have made and explain how you know.

HOW IS THIS The Fresnel lens is a "skinny" lens. Only one side of the USEFUL? lens is curved. This side is made up of a series of rings each of which has a curvature that is the same as the curve of a regular lens with the same focal length. The Fresnel lens is often used where a big lens that is light in weight is needed.

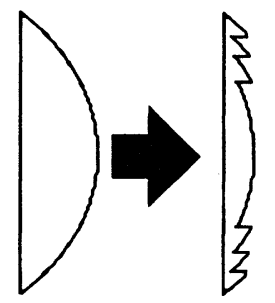

F988 Optical Society of Americs

Fig. 1. Example of experiment format in the OSA Optics Discovery Kit. 


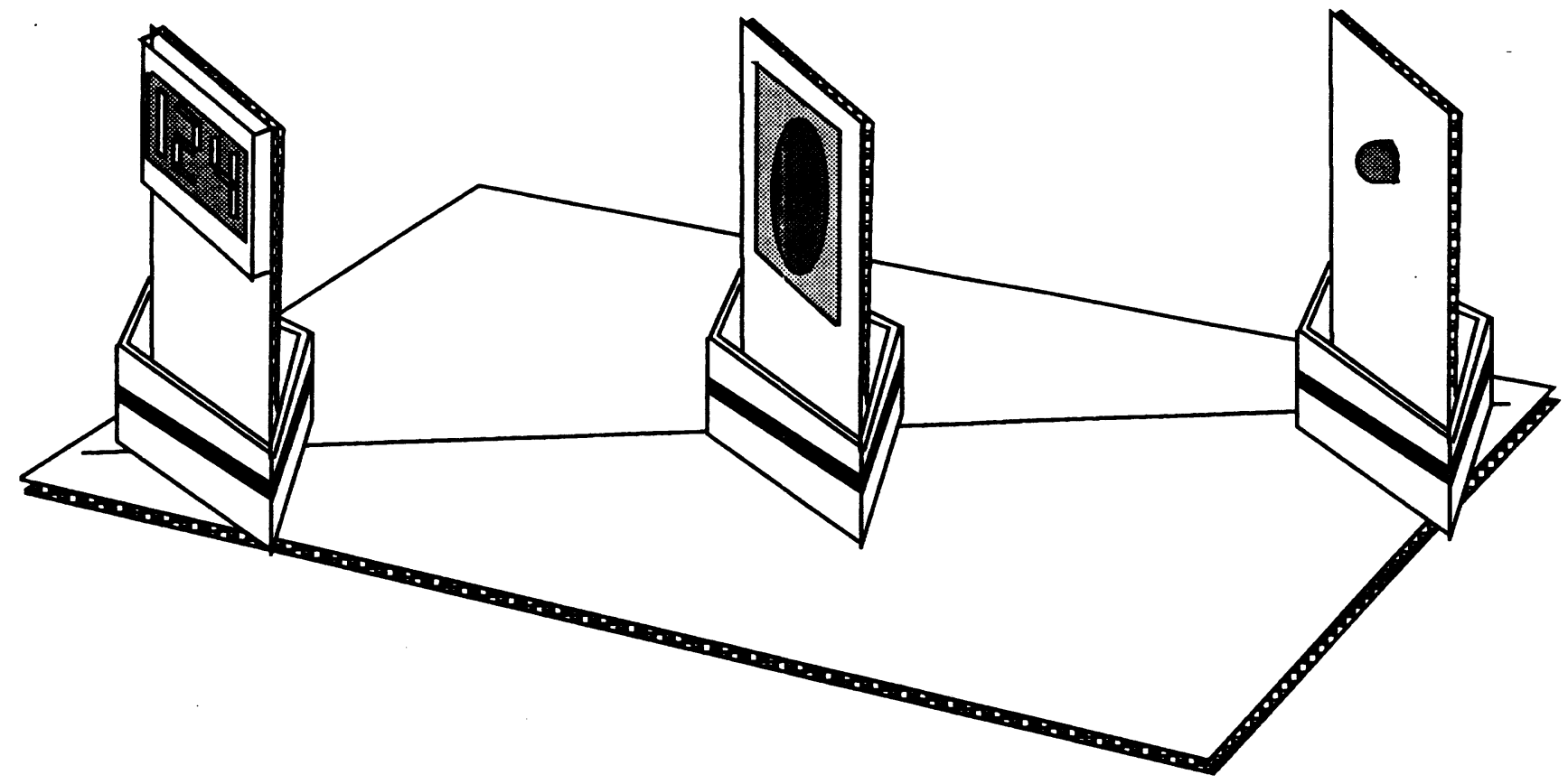

Fig. 2. The cardboard lens bench.

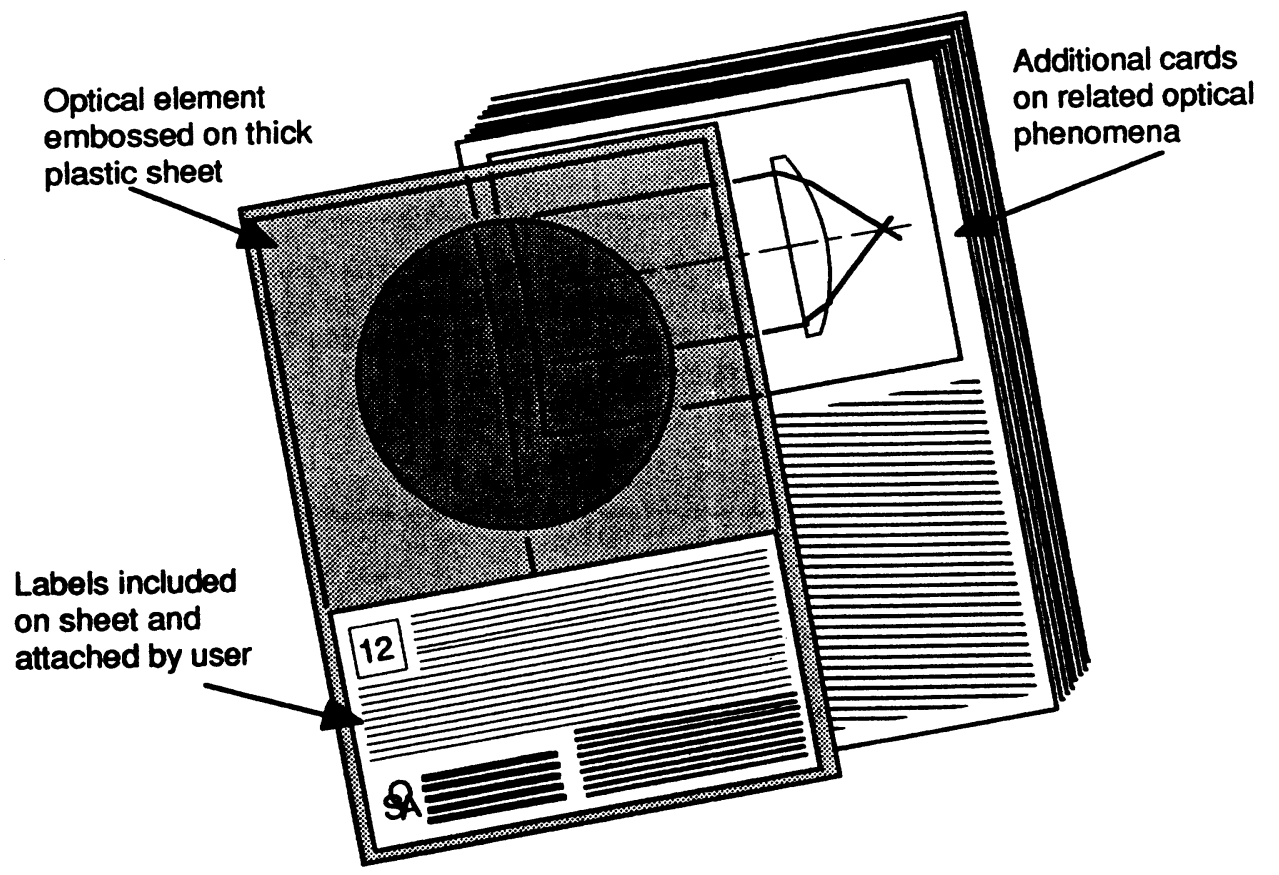

Fig. 3. Optics Trading Cards! 